\title{
Aspen Plus Simulation of Biomass Gasification with known Reaction Kinetic
}

\author{
M.S. Eikeland ${ }^{1} \quad$ R.K. Thapa ${ }^{1} \quad$ B.M. Halvorsen ${ }^{1}$ \\ ${ }^{1}$ Department of Process, Energy and Environmental Technology, Telemark University College, Norway, \\ ${ }^{1}$ marianne.eikelandehit.no
}

\begin{abstract}
The energy from biomass can be utilized through the thermochemical conversion processes of pyrolysis and gasification. The Aspen Plus simulation tool is applicable for simulation of the gasification processes.

The most common way is to simulate the gasification reactor using Gibbs reactor, which applies Gibbs free energy minimization to calculate equilibrium. The reactions in the gasification process are complex and by using the Gibbs reactor, it is not necessary to specify the stoichiometry or the reaction rates. However, reactions that describe the major conversion rates in a gasifier can be extracted from the literature. By using these reaction rates in Aspen Plus, it is possible to simulate the gasification process also by using a continuous stirred tank reactor (CSTR).

Comparison of the composition of produced gas based on simulation with Gibbs reactor and CSTR is performed. The influence of parameters like reactor temperature, residence time and steam flow rate are studied.
\end{abstract}

Keywords: gasification, Aspen Plus, reaction kinetic

\section{Introduction}

Biomass is an attractive source of energy. It is possible to utilize the energy through the thermo-chemical conversion processes of pyrolysis and gasification. In the pyrolysis process, the biomass is devolatilized by heat to char and volatiles. Depending on the feedstock, the volatiles include $\mathrm{H}_{2} \mathrm{O}, \mathrm{H}_{2}, \mathrm{~N}_{2}, \mathrm{O}_{2}, \mathrm{CO}_{2}, \mathrm{CO}, \mathrm{CH}_{4}$, $\mathrm{H}_{2} \mathrm{~S}, \mathrm{NH}_{3}, \mathrm{C}_{2} \mathrm{H}_{6}$ and very low levels of unsaturated hydrocarbons like acetylenes, olefins, aromatics and tars (Basu, 2008). Char has after the pyrolysis a higher carbon concentration than the dry feedstock. The char is converted to gases by using gasification agents like air, oxygen, carbon dioxide or steam.

There are different types of reactors used for gasification. Fluidized bed reactors are the most popular amongst them because of their high heat and mass transfer rates that result in high rate of produced gas. Steam gasification of wood using a dual fluidized bed reactor is one of the promising technologies for biomass conversion (Wilk, 2010; Hofbauer et al, 2002; Thapa, 2014). The principle of dual fluidized bed gasification process is shown in Figure 1.
The reactor is divided into two separate zones: combustion and gasification. The combustion zone is a circulating fluidized bed reactor where the fluidizing gas is air. In the combustion zone, inert bed materials, such as olivine particles or quartz sand, are heated by burning of char. The heated bed material is then circulated to the gasification reactor. The purpose of the recirculation of bed material is to supply necessary heat for the endothermic gasification reaction in the gasification zone.

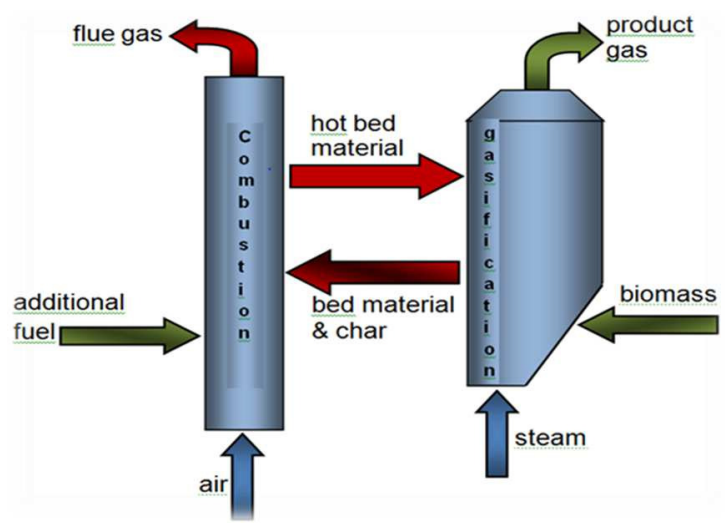

Figure 1. Principle of dual fluidized bed gasification technology (Thapa, 2014).

The gasification zone is a bubbling fluidized bed reactor for gasification of biomass. The fluidizing gas is high temperature steam. The biomass feed to the gasification reactor is mixed with hot bed materials. The biomass in the reactor is dried and devolatilized to produce volatile gases and solid char particles. The char particles react with steam to produce a mixture of combustible gases in addition to some $\mathrm{CO}_{2}$ and water vapour. The technology is developed by researchers at Vienna University of Technology. The technology is demonstrated as a successful story in the example of the biomass CHP plant in Güssing, Austria (Hofbauer et al, 2002).

Despite the novelty of the technology, the efficiency of the technology needs to be increased in order to make it sustainable and competitive in the world energy market. It is believed that the thermo-chemical process in the gasification reactor is one of the major factors that can increase the performance of the gasification process 
significantly. The thermo-chemical process in the reactor depends on a number of operating parameters as well as the design of the reactor. Experimental study of the thermo-chemical behaviour has been difficult due to high operating temperature in addition to time consumption and material costs related to the requirements of constructing hot models and pilot plants (Thapa, 2014).

The possibility to study the performance of the reactor by using simulation tools like Aspen Plus is valuable for a better understanding of the gasification process. A validated computational model could give an approximate answer to many factors effecting the efficiency of the plant.

Often, in literature, simulation models with Aspen Plus for gasification of biomass are performed in a Gibbs reactor where no reaction kinetics are applied (Doherty et al, 2013; Nikoo, 2008; Mavukwana et al, 2013). The Gibbs reactor uses Gibbs free energy minimization with phase splitting to calculate equilibrium. Gibbs reactor in Aspen Plus does not require specified reaction stoichiometry (Aspentech, 2010). This reduces the complexity of the process by ignoring the reactions taking place in the gasification process.

Xie and Umeki (Xie et al., 2013; and Umeki et al.,2010) have published a set of chemical reactions and their reaction rate expression as given in Table 1 . The set of equations describes the major conversion rates in a gasifier. The gasification process can be simulated in Aspen Plus by using a continuous stirred tank reactor (CSTR) and including the stoichiometric equations and the related reaction rates.

This work is focused on the analysis of the thermochemical process in the gasification reactor and the effect of implying the reaction kinetics in the Aspen Plus model of the process. The continuous stirred tank reactor and the Gibbs reactor are utilized as gasifiers to study the composition and the heating value of the produced gas. The aim is to develop a model, which gives a good approximation to the gasification reactor.

Table 1. Reaction kinetics for the major conversion rates in a gasifier reactor (Xie et al., 2013 and Umeki et al.,2010).

\begin{tabular}{|c|c|}
\hline Reactions & Reaction rate \\
\hline $\begin{array}{l}\frac{\text { Water-gas reaction: }}{\mathrm{C}(\mathrm{s})+\mathrm{H}_{2} \mathrm{O} \rightarrow \mathrm{CO}+\mathrm{H}_{2}} \\
\mathrm{CO}+\mathrm{H}_{2} \rightarrow \mathrm{C}(\mathrm{s})+\mathrm{H}_{2}\end{array}$ & $\begin{array}{l}r=1,272 * m_{S} * T * \exp \left(\frac{-22645}{T}\right)\left[\mathrm{H}_{2} \mathrm{O}\right] \\
r=1,044 * 10^{-4} * m_{S} * T^{2} * \exp \left(\frac{-6319}{T}-17,29\right)\left[\mathrm{H}_{2}\right][\mathrm{CO}]\end{array}$ \\
\hline $\begin{array}{l}\text { Boudouard reaction: } \\
\mathrm{C}(\mathrm{s})+\mathrm{CO}_{2} \rightarrow 2 \mathrm{CO} \\
2 \mathrm{CO} \rightarrow \mathrm{C}(\mathrm{s})+\mathrm{CO}_{2}\end{array}$ & $\begin{array}{l}r=1,272 * m_{s} * T * \exp \left(\frac{-22645}{T}\right)\left[\mathrm{CO}_{2}\right] \\
r=1,044 * 10^{-4} * m_{s} * T^{2} * \exp \left(\frac{-2363}{T}-20,92\right)[\mathrm{CO}]^{2}\end{array}$ \\
\hline $\begin{array}{l}\text { Methanation reaction: } \\
0,5 \mathrm{C}(\mathrm{s})+\mathrm{H}_{2} \rightarrow 0,5 \mathrm{CH}_{4} \\
0,5 \mathrm{CH}_{4} \rightarrow 0,5 \mathrm{C}(\mathrm{s})+\mathrm{H}_{2}\end{array}$ & $\begin{array}{l}r=1,368 * 10^{-3} * m_{s} * T * \exp \left(\frac{-8078}{T}-7,087\right)\left[H_{2}\right] \\
r=0,151 * m_{s} * T^{0,5} * \exp \left(\frac{-13578}{T}-0,372\right)\left[C H_{4}\right]^{0,5}\end{array}$ \\
\hline $\begin{array}{l}\text { Water gas shift reaxtion: } \\
\mathrm{CO}+\mathrm{H}_{2} \mathrm{O} \rightarrow \mathrm{CO}_{2}+\mathrm{H}_{2} \\
\mathrm{CO}_{2}+\mathrm{H}_{2} \rightarrow \mathrm{CO}+\mathrm{H}_{2} \mathrm{O}\end{array}$ & $\begin{array}{l}r=7,68 * 10^{10} * T * \exp \left(\frac{-36640}{T}\right)[\mathrm{CO}]^{0,5}\left[\mathrm{H}_{2} \mathrm{O}\right] \\
r=6,4 * 10^{9} * T * \exp \left(\frac{-39260}{T}\right)\left[\mathrm{H}_{2}\right]^{0,5}\left[\mathrm{CO}_{2}\right]\end{array}$ \\
\hline $\begin{array}{l}\text { Methane-reforming: } \\
\mathrm{CH}_{4}+\mathrm{H}_{2} \mathrm{O} \rightarrow \mathrm{CO}+3 \mathrm{H}_{2} \\
\mathrm{CO}+3 \mathrm{H}_{2} \rightarrow \mathrm{CH}_{4}+\mathrm{H}_{2} \mathrm{O}\end{array}$ & $\begin{array}{l}r=3,1005 * \exp \left(\frac{-15000}{T}\right)\left[\mathrm{CH}_{4}\right]\left[\mathrm{H}_{2} \mathrm{O}\right] \\
r=3,556 * 10^{-3} * T * \exp \left(\frac{-15000}{T}\right)[\mathrm{CO}]\left[\mathrm{H}_{2}\right]^{2}\end{array}$ \\
\hline
\end{tabular}

\section{Theory}

The thermodynamic equilibrium model predicts the maximum achievable yield of a desired product from a reacting system (Li et al, 2001; Basu, 2013). The reactants are left to react for an infinite of time and will reach the equilibrium yield. In practice, only a finite time is available for the reactant to react in the gasification reactor, so for practical purpose a kinetic model must be used to predict the product composition after a certain time of reaction.

Thermodynamic equilibrium calculation is independent of the gasifier design and is convenient to use to study the influence of fuel and process parameters. Thermodynamic or chemical equilibrium may not be reached in the gasifier, but the simulations may provide reasonable prediction of the maximum achievable yield of the desired product. Minimization of Gibbs free energy (non-stoichiometric model) can be used to determine chemical equilibrium. The only input 
needed is the elemental composition of the feed, which is known from its ultimate analysis (Basu, 2013).

In a kinetic model the gas yield and the product composition from a gasifier is determined after a finite time of reaction. Reaction rate and reactor residence time is included in the model. The kinetic rates determine how fast the reaction products are formed and whether the reactions are completed in the gasifier.

There are many chemical reactions taking place in a gasification reactor. For simplification, it is assumed that a set of reactions describes the major conversion rates in the reactor (Xie et al., 2013). The solids are consumed and the particles shrinks by heterogeneous chemistry reactions of gasification and methanation. (Xie et al., 2013). The reaction kinetics, given in Table 1 , show that the water gas-shift reaction and methanereforming reactions are rate determining for this set of reactions. The most common gas-solid reactions in the gasification zone are the Boudouard reaction, the watergas reaction and the methanation reaction as described in Table 1. Typical temperature range in the gasification zone in a fluidized bed is $700-900{ }^{\circ} \mathrm{C}$.

Table 2 gives the heats of reaction for the major conversion reactions in a gasifier (Moulijn et al, 2013).

Table 2. Heats of reaction for the major conversion rates in a gasifier reactor (Moulijn et al, 2013).

\begin{tabular}{|l|l|}
\hline & $\Delta H^{\circ} 800^{\circ} \mathrm{C}[\mathrm{kJ} / \mathrm{mol}]$ \\
\hline $\mathrm{C}(\mathrm{s})+\mathrm{H}_{2} \mathrm{O} \rightarrow \mathrm{CO}+\mathrm{H}_{2}$ & 136 \\
\hline $\mathrm{C}(\mathrm{s})+\mathrm{CO}_{2} \rightarrow 2 \mathrm{CO}$ & 173 \\
\hline $\mathrm{C}(\mathrm{s})+2 \mathrm{H}_{2} \rightarrow \mathrm{CH}_{4}$ & -87 \\
\hline $\mathrm{CO}+\mathrm{H}_{2} \mathrm{O} \rightarrow \mathrm{CO}_{2}+\mathrm{H}_{2}$ & -37 \\
\hline $\mathrm{CH}_{4}+\mathrm{H}_{2} \mathrm{O} \rightarrow \mathrm{CO}+3 \mathrm{H}_{2}$ & 228 \\
\hline
\end{tabular}

The reaction with steam is highly endothermic. Also the reaction with carbon dioxide gasification is endothermic, while the methanation and the water gas shift reactions are exothermic.

\section{Model description}

Zanzi, 2002, reported the yield products obtained in rapid pyrolysis for wood, birch, as shown in Table 3. These data have been used to define the composition of the feed into the gasification reactor. Table 4 gives the composition of the gaseous products on a nitrogen and water free basis. The data in Table 3 and 4 are converted to weight fractions, where $\mathrm{H}_{2}, \mathrm{CH}_{4}, \mathrm{CO}$ and $\mathrm{CO}_{2}$ are assumed to be gas yield, while the other components are added to tar. As an average component, $\mathrm{C}_{3} \mathrm{H}_{6}$ is used in the Aspen Plus simulation as tar component, and solid carbon is used as char.
Table 3. Yield of products obtained in rapid pyrolysis of birch (maf: moisture and ash free), (Zanzi, 2002).

\begin{tabular}{|l|l|}
\hline Temperature ${ }^{\circ} \mathrm{C}$ & 800 \\
\hline Gas Yield wt\% maf & 77.7 \\
\hline Tar yield wt\% maf & 1.1 \\
\hline Char yield wt\% maf & 7.2 \\
\hline Moisture wt\% & 14 \\
\hline
\end{tabular}

Table 4. Composition of the gaseous products (vol \%) on a nitrogen and water free basis in rapid pyrolysis at $800{ }^{\circ} \mathrm{C}$ (Zanzi, 2002).

\begin{tabular}{|l|l|}
\hline Gas & vol\% \\
\hline $\mathrm{H}_{2}$ & 16.8 \\
\hline $\mathrm{CH}_{4}$ & 16.2 \\
\hline $\mathrm{CO}_{2}$ & 8.3 \\
\hline $\mathrm{CO}$ & 50.7 \\
\hline $\mathrm{C}_{2} \mathrm{H}_{2}, \mathrm{C}_{2} \mathrm{H}_{4}$ & 6.2 \\
\hline $\mathrm{C}_{2} \mathrm{H}_{6}$ & 0.3 \\
\hline Benzene & 1.2 \\
\hline Other & 0.3 \\
\hline
\end{tabular}

The feed composition in Aspen Plus is specified as presented in Table 5. The feed temperature is $800^{\circ} \mathrm{C}$ and pressure is set to 1 bar.

Table 5. Mass fraction from birch wood used in Aspen plus simulation

\begin{tabular}{|l|l|l|}
\hline Gas & $\begin{array}{l}\text { Mixed } \\
\text { substream } \\
\text { [mass-frac] }\end{array}$ & $\begin{array}{l}\text { CISolid } \\
\text { substream } \\
\text { [mass-frac] }\end{array}$ \\
\hline $\mathrm{CH}_{4}$ & 0.0969 & 0 \\
\hline $\mathrm{CO}$ & 0.5307 & 0 \\
\hline $\mathrm{CO}_{2}$ & 0.1365 & 0 \\
\hline $\mathrm{H}_{2}$ & $0 ., 0125$ & 0 \\
\hline $\mathrm{C}$ & 0 & 1 \\
\hline $\mathrm{H} 2 \mathrm{O}$ & 0.1509 & 0 \\
\hline $\mathrm{C}_{3} \mathrm{H}_{6}$ & 0.0725 & 0 \\
\hline
\end{tabular}

The following assumptions were made for the Aspen simulation:

- The system is isothermal and operates under steady state conditions.

- Operation at atmospheric pressure, pressure drops are neglected.

- Nitrogen, sulphur, chlorine and ash are neglected.

- Tar formation is not considered.

- Char is $100 \%$ carbon.

- Heat loss from the gasifier is neglected. 


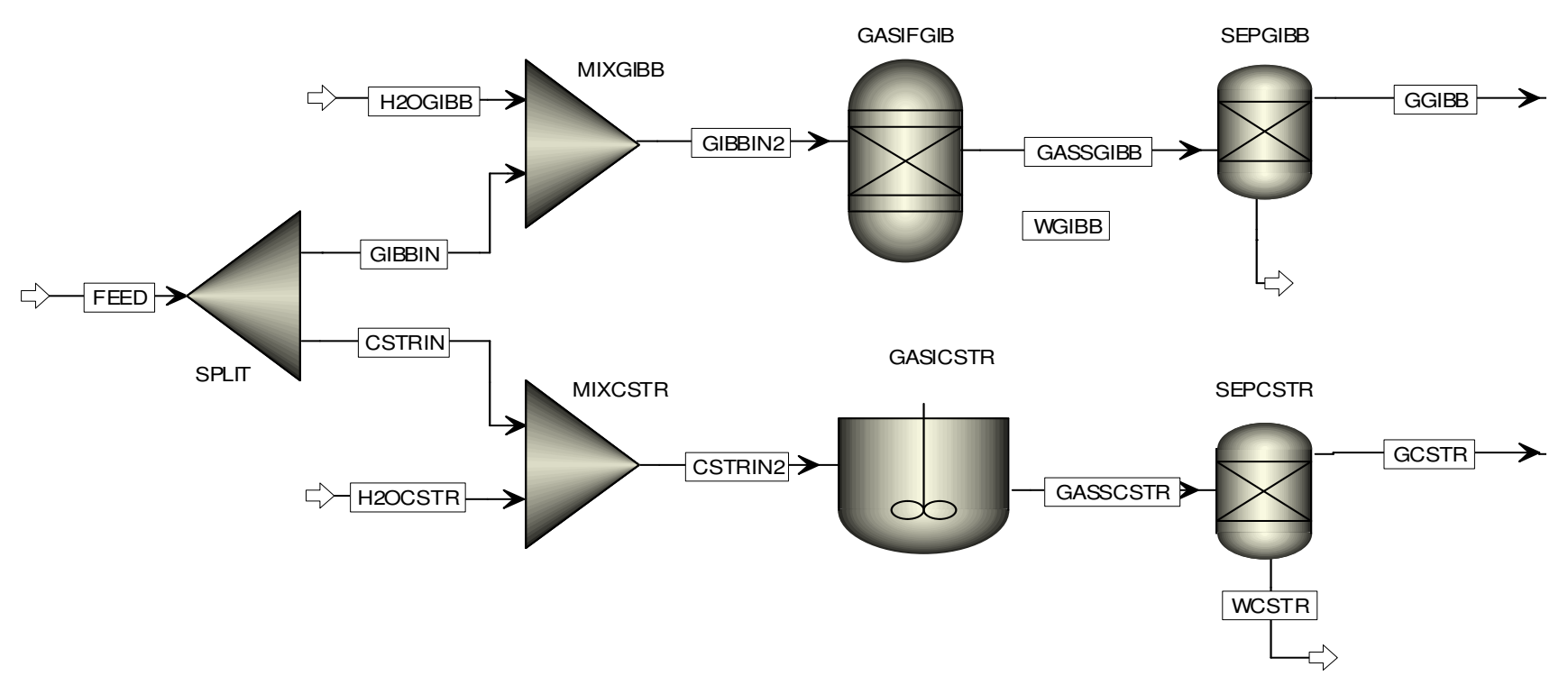

Figure 2. The Aspen Plus process flow sheet.

The stream class used in Aspen Plus is MIXCISLD and the property method used is Redlich-Kwong-Soave (RKS) cubic equation of state with Boston-Mathias alpha function (RKS-BM). The RKS-BM property method is recommended for gas processing, refinery, and petrochemical applications. The RKS-BM property method is used for nonpolar or mildly polar mixtures. Examples are hydrocarbons and light gases, such as carbon dioxide, hydrogen sulphide, and hydrogen. The RKS-BM property method is consistent in the critical region. The results have the lowest accuracy in the region near the mixture critical point (Aspentech, 2010).

\subsection{Flow Sheet}

The Aspen Plus flow sheet used in the simulation is presented in Figure 2. The feed composition is defined as described in Table 5.

The feed is split into two equal streams, which is directed to two different reactors: Gibbs reactor and CSTR. The flow is entering a mixer where the gasification agent, in this case steam, is added before entering the gasification reactor. After the reactor, water is removed to determine the gas composition on a dry basis.

For the Gibbs reactor, the reactions presented in Table 2 were specified in the reactor setup with a temperature approach of $0^{\circ} \mathrm{C}$, meaning that the calculation is done at reactor temperature. For the CSTR the reactions stoichiometry and their reaction rates are defined in the reaction setup in Aspen Plus, and the residence time is defined in the reactor setup.

Information about the process parameters are given in Table 6. The parameters are based on the same dimensions used in the work of Thapa, 2014.

\section{Reaction rates}

Table 1 refers to the reaction rates given by Xie and Umeki (Xie et al., 2013 and Umeki et al.,2010). Chemical reactions are expressed by stoichiometric equations and reaction rates are described in terms of a power law format. The rate coefficients based on Arrhenius law are empirically fitted with measured data (Xie et al., 2013).

Table 6. Process parameters used in Aspen Plus simulation (Thapa, 2014).

\begin{tabular}{|l|l|l|}
\hline & Gibbs & CSTR \\
\hline Feed in pr. reactor $[\mathrm{kg} / \mathrm{h}]$ & 112 & 112 \\
\hline Steam in pr. reactor $[\mathrm{kg} / \mathrm{h}]$ & 112 & 112 \\
\hline Volume reactor $\left[\mathrm{m}^{3}\right]$ & & 0,4752 \\
\hline Reactor temperature $\left[{ }^{\circ} \mathrm{C}\right]$ & 850 & 850 \\
\hline Reactor pressure $[\mathrm{bar}]$ & 1 & 1 \\
\hline
\end{tabular}

The Arrhenius coefficient is expressed as:

$$
k=A_{0} m_{S}^{C 1} T^{C 2} \exp \left(-\frac{E}{R T}+E_{0}\right)
$$

Where $\mathrm{k}$ is the chemical reaction rate coefficient, $\mathrm{A}_{0}$ is the pre-exponential factor, $\mathrm{E}[\mathrm{J} / \mathrm{mole}]$ is the activation energy, $\mathrm{E}_{0}$ is the activation energy constant, $\mathrm{R}[\mathrm{J} / \mathrm{mole}$ $\mathrm{K}]$ is the universal gas constant and $\mathrm{C} 1$ and $\mathrm{C} 2$ are constants. $\mathrm{T}[\mathrm{K}]$ denotes the temperature and $\mathrm{m}_{\mathrm{s}}[\mathrm{kg}]$ is the solid mass of fixed carbon per volume (Xie et al., 2013). In this work the following assumption is made:

$$
m_{s}=\mathrm{M}_{\mathrm{wC}} * C(s)
$$

where $\mathrm{M}_{\mathrm{wC}}$ is the molecular weight of carbon [ $\left.\mathrm{kg} / \mathrm{kmol}\right]$, and $\mathrm{C}(\mathrm{s})$ is molar concentration of solid carbon $\left[\mathrm{kmol} / \mathrm{m}^{3}\right]$. 
Aspen Plus provides a built-in power law expression for calculation of the rate of reaction. The general power law expression is:

$$
\text { Kinetic factor }=k\left(\frac{T}{T_{0}}\right) \exp \left(-\frac{E}{R}\left(\frac{1}{T}-\frac{1}{T_{0}}\right)\right.
$$

If the reference temperature $T_{0}[K]$ is not specified, Aspen Plus uses the reduced power law expression:

$$
\text { Kinetic factor }=k T^{n} \exp \left(-\frac{E}{R T}\right)
$$

\section{Results and discusion}

The results of the simulations are given in Table 8 . The results are compared with typical composition of the produced gas from the biomass gasification plant in Güssing, Austria (Güssing Renewable Energy). The results from the gasification plant are based on wood chips.

\begin{tabular}{|c|c|c|c|}
\hline & CSTR & Gibb & $\begin{array}{c}\text { Experimental } \\
\text { data (Güssing } \\
\text { Renewable } \\
\text { Energy) }\end{array}$ \\
\hline Residence time [s] & 1.7 & & \\
\hline $\begin{array}{l}\mathrm{CH}_{4}(\text { vol \% dry } \\
\text { basis) }\end{array}$ & 16.4 & 0.012 & $\sim 10$ \\
\hline $\begin{array}{l}\mathrm{CO} \text { (vol \% dry } \\
\text { basis) }\end{array}$ & 44.1 & 25.8 & $\sim 24$ \\
\hline $\begin{array}{l}\mathrm{CO}_{2}(\text { vol } \% \text { dry } \\
\text { basis) }\end{array}$ & 15.6 & 16.8 & $\sim 23$ \\
\hline $\begin{array}{l}\mathrm{H}_{2}(\text { vol \% dry } \\
\text { basis) }\end{array}$ & 24.0 & 57.5 & $\sim 44$ \\
\hline LHV $\left[\mathrm{MJ} / \mathrm{m}^{3}\right]$ & 14.0 & 9.5 & $\sim 13-15$ \\
\hline $\begin{array}{l}\text { Volume } \\
\text { reactor }\left[\mathrm{m}^{3}\right]\end{array}$ & 0.48 & & \\
\hline $\begin{array}{l}\text { Gasification } \\
\text { temperature }\left[{ }^{\circ} \mathrm{C}\right]\end{array}$ & 850 & 850 & 850 \\
\hline
\end{tabular}

Table 8. Results of the main components after gasification

\subsection{Steam flow}

A sensitivity analysis of volume fraction (dry basis) composition in the produced gas as function of steam flow is performed in Aspen Plus. The results are presented in Figure 3. Both the CSTR and the Gibbs reactors show a decrease in $\mathrm{CO}$ concentration as a function of steam rate, but a steeper decrease is observed in the Gibbs reactor compared to the CSTR. $\mathrm{CH}_{4}$ concentrations is also decreasing in both cases, but in the Gibbs reactor the concentration of $\mathrm{CH}_{4}$ is approaching zero, while the methane concentration in the CSTR will be about $13 \%$. $\mathrm{H}_{2}$ and $\mathrm{CO}_{2}$ concentrations increase when the steam flow increases in both the cases. However, the $\mathrm{H}_{2}$ concentration within a Gibbs reactor can reach over $60 \%$, while the $\mathrm{H}_{2}$ concentration with the same amount of water will be less than $30 \%$ in a CSTR. The $\mathrm{CO}_{2}$ concentration will also be higher in a Gibbs reactor compared to the CSTR. The residence time in CSTR is $1.7 \mathrm{~s}$, giving a finite time for the reactions to be completed.

An increase in the steam flowrate results in production of $\mathrm{CO}, \mathrm{CO}_{2}$ and $\mathrm{H}_{2}$ related to the Le Chateliers principle. However, in the water gas shift reaction $\mathrm{CO}$ is consumed, thus $\mathrm{CO}_{2}$ and $\mathrm{H}_{2}$ will be the dominating products based on chemical equilibrium. For the kinetics, the water gas shift reaction has the dominating reaction rate and here $\mathrm{CO}$ will also be consumed. However, this reaction is exothermic and the reaction will therefore go to the left direction when the reaction temperature is high. This will imply that less $\mathrm{CO}$ is consumed when the kinetics are considered, and consequently less $\mathrm{CO}_{2}$ and $\mathrm{H}_{2}$ are produced.

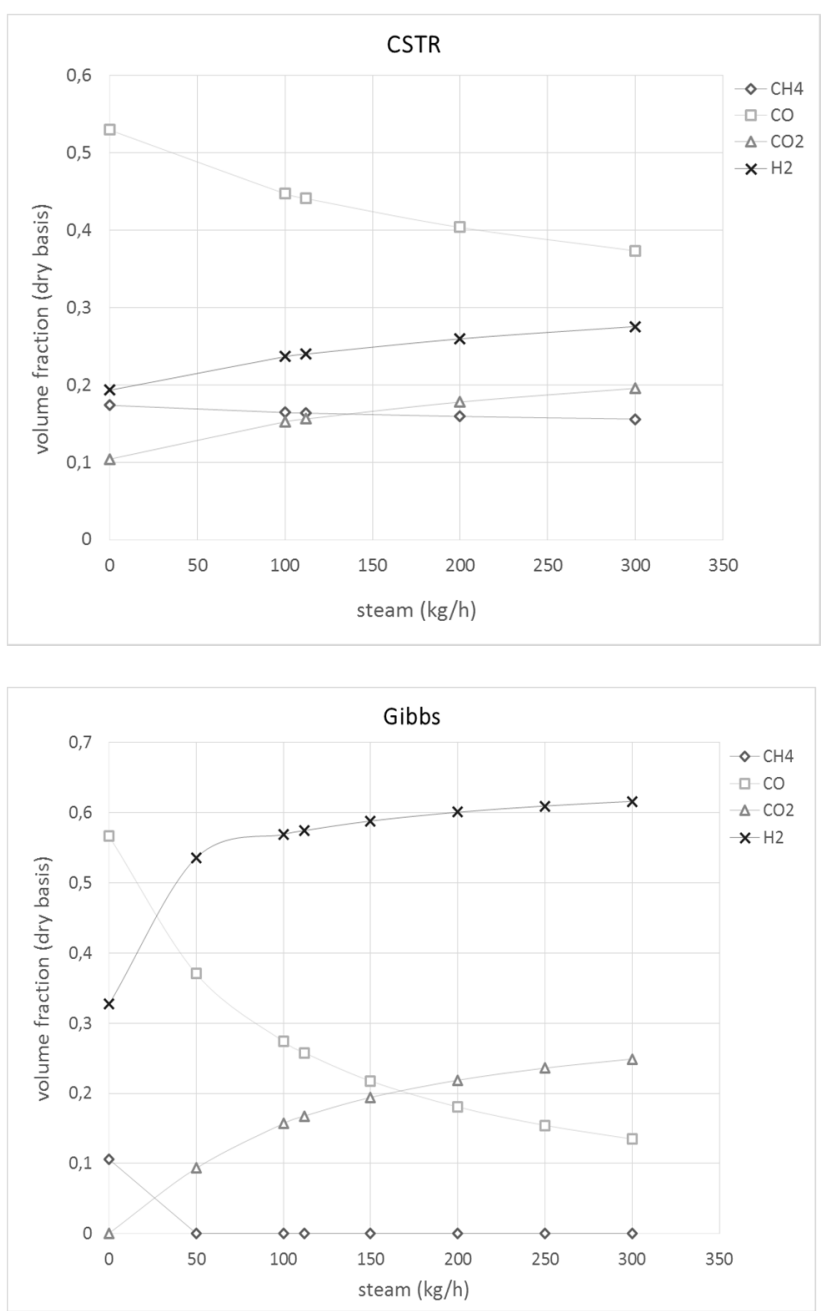

Figure 3. Steam $(\mathrm{kg} / \mathrm{h})$ as function of volume fraction (dry basis) of $\mathrm{CH}_{4}, \mathrm{CO}, \mathrm{CO}_{2}$ and $\mathrm{H}_{2}$ simulated by Aspen Plus for CSTR and Gibbs reactor. Reactor temperature $850^{\circ} \mathrm{C}$. 


\subsection{Temperature}

Variation of temperature in the gasification reactors will influence on the composition of the produced gas. Figure 4 shows the composition of the gas as a function of the temperature in the reactor.

The $\mathrm{CO}$ concentration increases in the Gibbs reactor, but decreases in CSTR when temperature increases. $\mathrm{CH}_{4}$ decreases in both cases, but in a lesser degree in CSTR. $\mathrm{CO}_{2}$ increases in the CSTR, but decreases in Gibbs. $\mathrm{H}_{2}$ increases in CSTR, but in the Gibbs reactor $\mathrm{H}_{2}$ increases with temperature up to $700^{\circ} \mathrm{C}$ and decreases slightly at higher temperatures. Also, notice that the change of composition in the CSTR is largest in the temperature interval of $800-1000^{\circ} \mathrm{C}$.
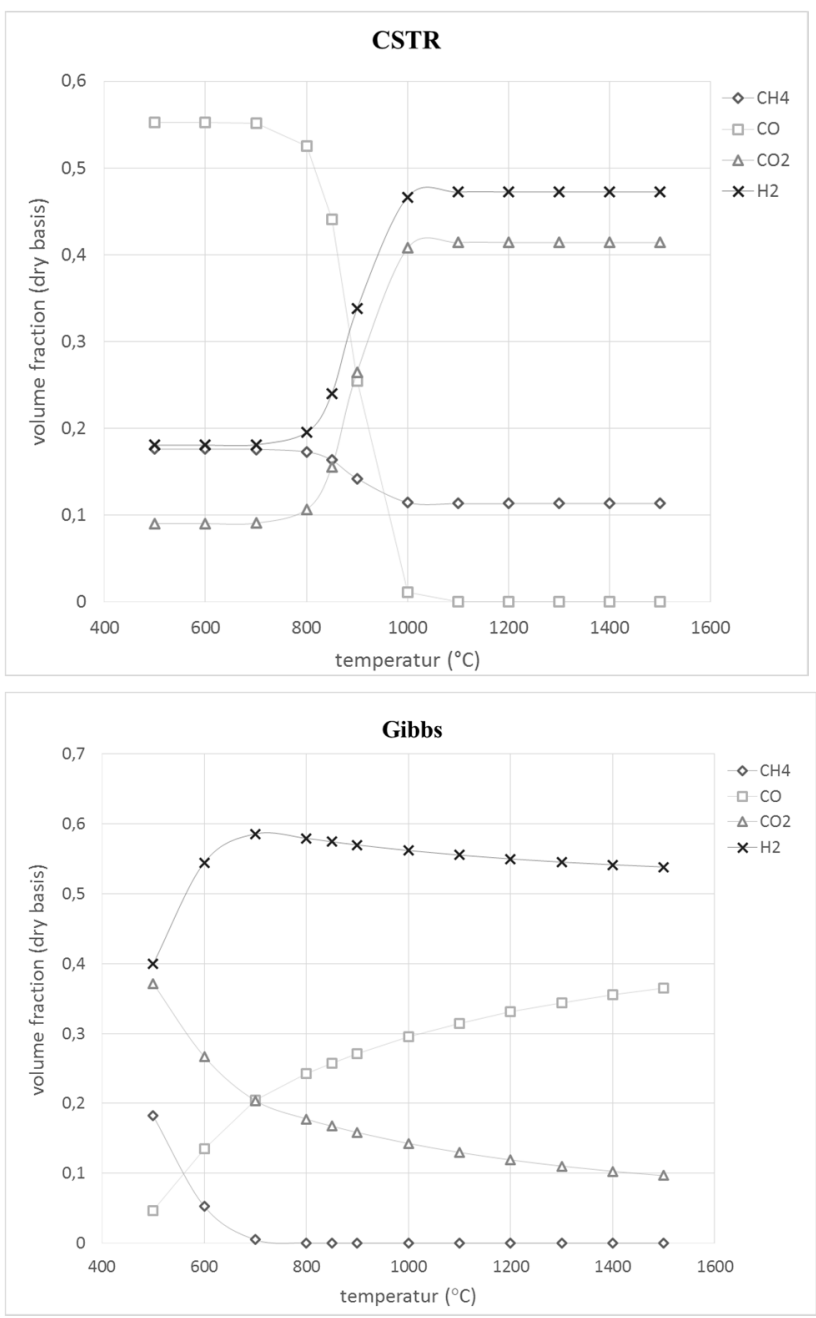

Figure 4. Temperature $\left({ }^{\circ} \mathrm{C}\right)$ as function of volume fraction (dry basis) of $\mathrm{CH}_{4}, \mathrm{CO}, \mathrm{CO}_{2}$ and $\mathrm{H}_{2}$ simulated by Aspen Plus. Steam $112 \mathrm{~kg} / \mathrm{h}$.

The differences in temperature profiles for the two reactors can be explained due to thermodynamics and kinetics. In a Gibbs reactor, where the thermodynamic or chemical equilibrium is reached, a temperature increase will favour the endothermic reactions. The water-gas reaction, the Boudouard reaction and the methane-reforming reaction, all of them having a positive heat of reaction (Table 2), are endothermic reactions. These three sets of reactions will favour a production of $\mathrm{CO}$ and $\mathrm{H}_{2}$ and consumption of methane.

The methanation and the water gas shift reactions are both exothermic. Increasing the temperature for these reactions will make the heat content of the system to increase. The system will then consume some of that heat by shifting the equilibrium to the left as described by Le Chateliers principle. This will lead to a reduction of the $\mathrm{CO}_{2}$ and $\mathrm{CH}_{4}$ concentrations. This describes the profiles that can be observed in the Gibbs reactor.

For the CSTR the temperature profiles are different due to the kinetics defined for the reactions. All of the reaction rates are temperature dependent in different extent. An increase in temperature gives a decrease in the exponential factor of the reaction rate expression. The water gas shift reaction has the dominating reaction rate implying a consumption of $\mathrm{CO}$ and production of $\mathrm{CO}_{2}$ and $\mathrm{H}_{2}$. It can also be observed that $\mathrm{CH}_{4}$ is consumed in the methane reforming reaction to produce $\mathrm{H}_{2}$ and $\mathrm{CO}$.

Inflection point for all the reaction sets are typical at around $800^{\circ} \mathrm{C}$ and is the reason for the steep increase /decrease in concentrations around this temperature.

\subsection{Residence time}

Residence time or reactor volume will influence on the composition of produced gas from the gasifier. A longer residence time will give the reactions more time to reach equilibrium. To increase the residence time it is necessary to either increase the reactor volume or reduce the feed inlet flow to the reactor. Figure 5 gives the composition of produced gas at different residence times in CSTR.

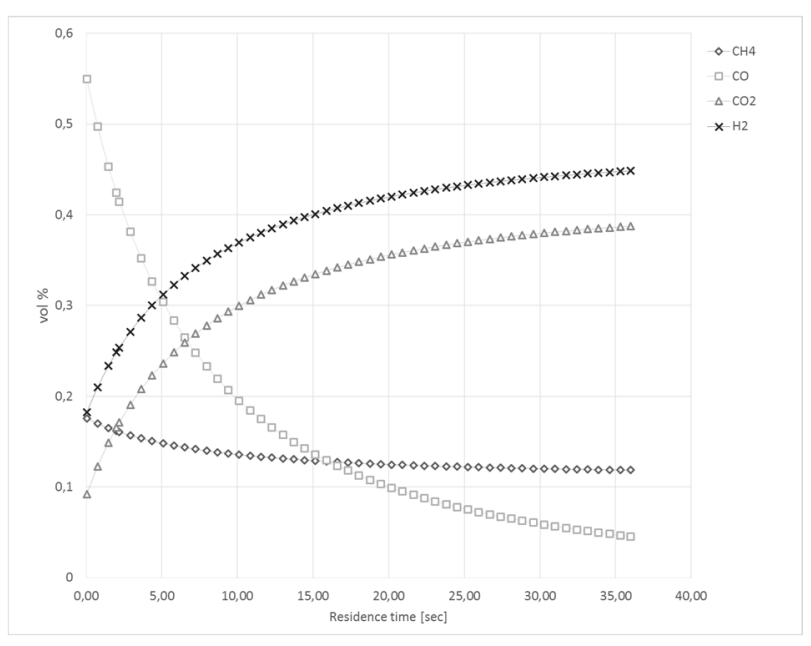

Figure 5. Residence time (s) as function of volume fraction (dry basis) of $\mathrm{CH}_{4}, \mathrm{CO}, \mathrm{CO}_{2}$ and $\mathrm{H}_{2}$ simulated by Aspen Plus. Steam flow $112 \mathrm{~kg} / \mathrm{h}$, temperature $850^{\circ} \mathrm{C}$. 
Increased residence gives a higher $\mathrm{H}_{2}$ and $\mathrm{CO}_{2}$ concentration, while $\mathrm{CH}_{4}$ and $\mathrm{CO}$ concentrations decrease with residence time. A residence time of about 8 sec. gives a comparable gas composition to the experimental data from Güssing, with $14 \mathrm{vol} \% \mathrm{CH}_{4}, 23$ vol \% $\mathrm{CO}, 28$ vol $\% \mathrm{CO}_{2}$ and 35 vol\% $\mathrm{H}_{2}$.

\section{Conclusion}

Simulation of the gasification process in Aspen Plus is useful in studying the produced gas composition. The simulations using Gibbs rector and CSTR as models for the fluidized gasification rector show how the composition of the produced gas differs because of the different principles in the two methods. Gibbs reactor is based on minimizing free energy and chemical and thermodynamic equilibrium are reached. In the CSTR, it is necessary to define the reaction rates of the actual reactions taking place in the reactor. The kinetics will determine how fast the reaction is approaching and the residence time will determine whether the equilibrium conditions are obtained.

The product gas composition obtained from simulation of the gasification reactions using Gibb's reactor and CSTR are compared with data from the Güssing plant. The lower heating value of the product gas agree well for the three cases, but the gas compositions show some deviations. Sensitivity analysis for the product gas composition have been performed with respect to steam flow rate, reaction temperature and residence time. In both the Gibb's and CSTR reactor, the concentration of $\mathrm{CO}$ and $\mathrm{CH}_{4}$ decreases whereas the concentration of $\mathrm{CO}_{2}$ and $\mathrm{H}_{2}$ increases with increasing steam flow rate. In both of the reactors, the concentration of $\mathrm{CH}_{4}$ decreases with increasing temperature. In Gibb's reactor, $\mathrm{CO}$ concentration increases and $\mathrm{CO}_{2}$ concentration decreases with increasing temperature. These results are opposite of the results obtained from the CSTR reactor. The concentration of $\mathrm{H}_{2}$ and $\mathrm{CO}_{2}$ increases while the concentration of $\mathrm{CO}$ and $\mathrm{CH}_{4}$ decreases with increasing residence time in CSTR reactor.

The results from the simulation of the Gibbs reactor is based on calculations where the reactions reach thermodynamically and chemical equilibrium over an infinite of time. In a real process, the time of reactions is finite and the different reactions have different reaction rates. CSTR reactor will approach a more realistic description of the process. However, a further analysis of the simulation process is necessary to reach a good model for the gasification process compared to experimental data.

\section{References}

Aspen tech. Aspen Physical Property System, Physical Property Methods. Version Number: V7.2, July 2010.
Basu Prabir. Biomass Gasification, Pyrolysis and

Torrification, Practical Design and Theory. Second edition.

Academic Press. 2013.

Bolhar-Nordenkampf, M. and Hofbauer H. Gasification demonstration plants in Austria. IV. International Slovak Biomass Forum. 2004. Bratislava.

Doherty W., Reynolds A., Kennedy D. Aspen Plus Simulation of Biomass Gasification in a Steam Blown Dual Fluidised Bed. Materials and processes for energy: communicating current research and technological developments. Méndez-Vilas (Ed.). Formatex Research Centre. 2013.

Güssing Renewable Energy GmbH; GRE MULTIFUEL GASIFICATION http://www.gussingrenewable.com. 2014. Hofbauer, H., Rauch R., and Bosch K.. Biomass CHP Plant Gussing - A Success Story. Expert Meeting on Pyrolysis and Gasification of Biomass and Waste. 2002. Strasbourg, France.

Li X., Grace J.R., Watkinson A.p., Lim C.J. Ergündenler A. Equilibrium modeling of gasification: a free energy minimization approch and its application to a circulating fluidized bed coal gasifier. Fuel, 80, pp. 195-207. 2001.

Mavukwana A., Jalama K., Ntuli F., and Harding K. Simulation of Sugarcane Bagasse Gasification using Aspen Plus. International Conference on Chemical and Environmental Engineering (ICCEE'2013). 2013. Johannesburg, South Africa.

Nikoo M. B., Mahinpey N. Simulation of biomass gasification in fluidized bed reactor using ASPEN PLUS. Biomass and Bioenergy, volume 32, Issue 12, pp. 1245-1254. 2008.

Moulijn J. A., Makkee M., van Diepen A. Chemical process technology John Wiley \& Sons, pp. 143. 2013.

Thapa R. K., Halvorsen B. M. Stepwise analysis of reactions and reacting flow in a dual fluidized bed gasification reactor. Advances in Fluid Mechanics X, Volume 82, WIT Transactions on Engineering Sciences. 2014.

Umeki K.,Yamamoto K., Namioka T., Yoshikawa K. High temperature steam-only gasification of woody biomass. Applied Energy, 87, pp. 791-798. 2010.

Wilk V., Koppatz S., Pfeifer C., Hofbauer H. Gasification of residues and waste wood in a dual fluidised bed steam gasifier. ICPS 10 Proceedings. 2010.

Xie J., Zhong W., Jin B., Shao Y., Huang Y. EulerianLagrangian method for three-dimensional simulation of fluidized bed coal gasification. Advanced Powder Technology, 24, pp. 382-392. 2013.

Zanzi, R., Sjostrom K., and Bjornbom E. Rapid pyrolysis of agriculatural residues at high temperature. Biomass and Bioenergy, 23, pp. 357-366. 2002 
